doi: $10.2306 /$ scienceasia1513-1874.2010.36.231

\title{
Structural and electrical properties of
}

\section{$(1-x) \mathrm{Na}_{0.465} \mathrm{~K}_{0.465} \mathrm{Li}_{0.07} \mathrm{Nb}_{0.93} \mathrm{Ta}_{0.07} \mathrm{O}_{3}-x \mathrm{MnO}$ lead-free piezoelectric ceramics synthesized at low sintering temperatures}

\author{
Pornsuda Bomlai $^{\mathrm{a}, \mathrm{d}, *}$, Chanoknate Songsurin ${ }^{\mathrm{a}}$, Nantakan Muensit ${ }^{\mathrm{b}, \mathrm{d}}$, Steven J. Milne ${ }^{\mathrm{c}}$ \\ a Department of Materials Science and Technology, Faculty of Science, Prince of Songkla University, \\ Songkhla 90112 Thailand \\ b Department of Physics, Faculty of Science, Prince of Songkla University, Songkhla 90112 Thailand \\ c Institute for Materials Research, University of Leeds, Leeds LS2 9JT, UK \\ d NANOTEC Centre of Excellence at Prince of Songkla University, Thailand
}

*Corresponding author, e-mail: ppornsuda@yahoo.com

Received 24 Mar 2010

Accepted 20 Jun 2010

\begin{abstract}
Ceramics of the lead-free piezoelectric ceramic composition, $\mathrm{Na}_{0.465} \mathrm{~K}_{0.465} \mathrm{Li}_{0.07} \mathrm{Nb}_{0.93} \mathrm{Ta}_{0.07} \mathrm{O}_{3}$, (NKLNT), were prepared using a reaction sintering method. The effects of manganese oxide doping on the structural and electrical properties of NKLNT ceramics were investigated. Variations in the relative intensity of X-ray diffraction peaks were consistent with Mn ions substituting on the perovskite lattice to produce a change in the proportions of co-existing tetragonal and orthorhombic phases. Grain growth during secondary recrystallization was also affected, leading to more uniform microstructures. The temperature of the orthorhombic-tetragonal $(\mathrm{O}-\mathrm{T})$ phase transition decreased, and the Curie temperature increased as a result of Mn modifications. The dielectric dissipation factors were lowered by Mn incorporation, but the $d_{33}$ piezoelectric charge coefficient fell from $190 \mathrm{pC} / \mathrm{N}$ to $\leqslant 144 \mathrm{pC} / \mathrm{N}$ due to the shift in the O-T phase transition to well below room-temperature.
\end{abstract}

KEYWORDS: doping, phase formation, microstructure, dielectric and piezoelectric properties

\section{INTRODUCTION}

Lead zirconate titanate (PZT) based piezoelectric ceramics have been widely used in the manufacture of actuators, sensors, transducers, and other devices in recent years ${ }^{1-3}$. Because of the detrimental effects of $\mathrm{Pb}$ on human health, it is important that $\mathrm{Pb}$-free ferroelectric and piezoelectric materials are developed. The new environmentally acceptable and biocompatible materials should exhibit electrical properties comparable to those of $\mathrm{Pb}$-based ferroelectrics which have been developed over several decades.

Currently, sodium potassium niobate, $\left(\mathrm{Na}_{0.5} \mathrm{~K}_{0.5}\right) \mathrm{NbO}_{3}(\mathrm{NKN})$ based ceramics are one of the most promising alternative systems to PZT because of their excellent piezoelectric properties, high Curie temperature, and low environmental impact ${ }^{4-6}$. Research into these materials increased after Saito et $\mathrm{al}^{7}$ reported textured ( $\left.\mathrm{Li}, \mathrm{Sb}, \mathrm{Ta}\right)$ modified NKN ceramics with comparable piezoelectric properties $\left(d_{33}=416 \mathrm{pC} / \mathrm{N}, k_{\mathrm{p}}=61 \%\right)$ to a hard PZT.
However, it is well known that dense and well sintered NKN ceramics are very difficult to obtain by ordinary sintering processes because of the high volatility of alkali metal oxides at high temperatures. Therefore, many studies have been carried out to improve the densification and electrical properties of NKN ceramics, such as the formation of solid solutions with other oxides, e.g., $\mathrm{NKN}-\mathrm{BaTiO}_{3}{ }^{8}, \mathrm{NKN}-\mathrm{LiNbO}_{3}{ }^{9}$, NKN-LiSbO ${ }_{3}{ }^{10}, \mathrm{NKN}_{-} \mathrm{LiTaO}_{3}{ }^{11,12}, \mathrm{NKN}-\mathrm{LiTaO}_{3}-$ $\mathrm{LiSbO}_{3}{ }^{7,13}$. The effects of sintering aids such as $\mathrm{CuO}^{14}, \mathrm{ZnO}^{15}$, and $\mathrm{Bi}_{2} \mathrm{O}_{3}$ have also been studied ${ }^{16}$.

Although it was previously reported that the highest $d_{33}$ coefficients in the binary NKN-LT system are obtained at 5-6 mol\% $\mathrm{LiTaO}_{3}$, Skidmore et al ${ }^{17}$ showed that the NKN-7 mol\% $\mathrm{LiTaO}_{3}$ composition, $\left[\mathrm{Na}_{0.5} \mathrm{~K}_{0.5} \mathrm{NbO}_{3}\right]_{0.93}-\left[\mathrm{LiTaO}_{3}\right]_{0.07}$, offers more favourable temperature stability of dielectric and piezoelectric properties than the $5-6 \% \mathrm{LiTaO}_{3}$ ceramics. Moreover, the $d_{33}$ value for NKN-7 mol\% $\mathrm{LiTaO}_{3}, \sim 200 \mathrm{pC} / \mathrm{N}$, is similar to that of the 5$6 \mathrm{~mol} \% \mathrm{LiTaO}_{3}$ compositions. It has been reported 
that $\mathrm{MnO} / \mathrm{MnO}_{2}$ additions improve the densification and electrical properties of other NKN-based ceramics ${ }^{18-21}$. The multivalent additive suppresses grain growth and helps to increase the electrical resistivity of the piezoceramic. In this work, the effects of incorporating manganese oxide to $\left[\mathrm{Na}_{0.5} \mathrm{~K}_{0.5} \mathrm{NbO}_{3}\right]_{0.93}-$ $\left[\mathrm{LiTaO}_{3}\right]_{0.07}$ (abbreviated as NKLNT) are investigated.

\section{MATERIALS AND METHODS}

Sample compositions, $(1-x) \mathrm{Na}_{0.465} \mathrm{~K}_{0.465} \mathrm{Li}_{0.07}$ $\mathrm{Nb}_{0.93} \mathrm{Ta}_{0.07} \mathrm{O}_{3}-x \mathrm{MnO}$ with $x=0,0.005$, and 0.01 (i.e., $0,0.5$, and $1.0 \mathrm{~mol} \% \mathrm{MnO}$ ), were prepared by the conventional mixed oxide process using $\mathrm{Na}_{2} \mathrm{CO}_{3}$ (Sigma-Aldrich, 99.8-100\% purity), $\mathrm{K}_{2} \mathrm{CO}_{3}$, $\mathrm{Ta}_{2} \mathrm{O}_{5}$ (Sigma-Aldrich, 99\% purity), $\mathrm{Nb}_{2} \mathrm{O}_{5}, \mathrm{MnCO}_{3}$ (Sigma-Aldrich, $99.9 \%$ purity), and $\mathrm{Li}_{2} \mathrm{CO}_{3}$ (Fluka, $>99.0 \%$ purity), as the starting powders. A $\mathrm{Na}_{0.5} \mathrm{~K}_{0.5} \mathrm{NbO}_{3}$ powder was prepared before reacting with $\mathrm{Li}, \mathrm{Ta}$, and $\mathrm{Mn}$ reagents. The carbonate powders are moisture-sensitive; niobium and tantalum oxides can also form hydrated phases. Hence, to avoid compositional errors when weighing out the precursor mixture, the starting reagents were dried in an oven for $24 \mathrm{~h}$ before use. Dried powders were allowed to cool to room temperature under reduced pressure in a desiccator; all powders were stored in the desiccator until immediately prior to weighing in the correct proportions. The starting materials were transferred to a $100 \mathrm{~mm}$ diameter cylindrical plastic jar, partially filled with $10 \mathrm{~mm}$ diameter zirconia grinding balls. Sufficient ethanol was added to cover the powder/media. Ball milling was carried out for $24 \mathrm{~h}$, followed by drying at $120^{\circ} \mathrm{C}$. An alumina mortar and pestle was used to break up large agglomerates formed during drying. The mixtures were calcined in alumina crucibles with loosely fitting lids at $800^{\circ} \mathrm{C}$ for $2 \mathrm{~h}$. The NKN powders were then ground, weighed, and ball milled again for $24 \mathrm{~h}$ with $\mathrm{Ta}_{2} \mathrm{O}_{5}, \mathrm{Li}_{2} \mathrm{CO}_{3}$, and $\mathrm{MnCO}_{3}$ to obtain compositions $(1-x) \mathrm{Na}_{0.465}$ $\mathrm{K}_{0.465} \mathrm{Li}_{0.07} \mathrm{Nb}_{0.93} \mathrm{Ta}_{0.07} \mathrm{O}_{3}-x \mathrm{MnO}$, for 0 , 0.5, and $1.0 \mathrm{~mol} \% \mathrm{MnO}$ modifications $(x=0,0.005,0.01)$. A reaction-sintering approach was used to produce the NKLNT and MnO-modified ceramics, in that no second powder calcination step was employed. The combined powders were dried, ground, and pressed at $150 \mathrm{MPa}$ for $3 \mathrm{~min}$ into $1.5 \mathrm{~cm}$ diameter disks, placed in alumina crucibles, and sintered at temperatures ranging from $1025^{\circ} \mathrm{C}$ to $1075^{\circ} \mathrm{C}$ for $2 \mathrm{~h}$ in closed crucibles. Pellets were embedded in a NKLNT 'atmosphere' powder during sintering.

Ceramic samples were examined at room temperature using X-ray powder diffraction (XRD; Philips
X' Pert MPD, Ni-filtered $\mathrm{CuK}_{\alpha}$ radiation) to identify the phases formed. Sintered pellet densities were obtained by the Archimedes method. The microstructures of the as-sintered surfaces of the samples were imaged directly, using scanning electron microscopy (JEOL, Tokyo, JSM-5800LV). In order to investigate dielectric and piezoelectric properties, pellets were electroded with silver paste. The capacitance and dissipation factor $(D)$ of the samples were measured at $1 \mathrm{kHz}$ using an LCR meter (GW Instek; LCR 821) over the temperature range $25-500{ }^{\circ} \mathrm{C}$, from which the dielectric constant $\left(\varepsilon_{\mathrm{r}}\right)$ was calculated. For piezoelectric property measurements, the samples were polarized under a DC field of $3 \mathrm{kV} / \mathrm{mm}$ at $160^{\circ} \mathrm{C}$ in a silicone oil bath for $30 \mathrm{~min}$. The piezoelectric coefficient $\left(d_{33}\right)$ was then measured using a piezo- $d_{33}$ meter (APC International; YE2730A).

\section{RESULTS AND DISCUSSION}

Fig. 1 shows the XRD patterns of $(1-x)$ NKLNT$x \mathrm{MnO}$ samples which had been sintered at $1025^{\circ} \mathrm{C}$ for $2 \mathrm{~h}$. The intensity ratio of the pair of peaks at $2 \theta=45-46.5^{\circ}$ in each pattern was used as an indication of the tetragonal/orthorhombic phase content ${ }^{22}$. The lower angle peak in the pair corresponds to the (220) peak of an orthorhombic NKN-LT phase, or the (002) peak of the tetragonal phase of NKN-LT ${ }^{23,24}$. The neighbouring higher angle peak corresponds to the orthorhombic (002) peak, or the (200) peak of tetragonal NKN-LT. If the sample were singlephase tetragonal NKN-LT, from previous reports the intensity ratio of this pair of peaks $\left(I_{200} / I_{002}\right)$ is expected to be $\sim 2$. If the sample were single phase orthorhombic, the corresponding ratio (intensity of higher angle peak)/(intensity of lower angle peak), is expected to be $\sim 0.5^{22}$. Hence a mixture of

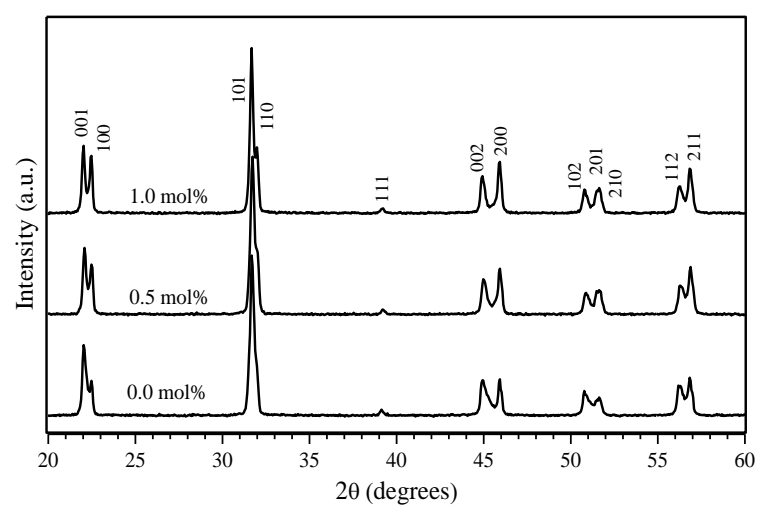

Fig. 1 XRD patterns of $(1-x)$ NKLNT $-x$ MnO ceramics sintered at $1025^{\circ} \mathrm{C}$. 
orthorhombic and tetragonal phases is expected from a measured intensity ratio of $\sim 1.0$, determined here for the $2 \theta=45-46.5^{\circ}$ peaks in the XRD pattern of the sample of unmodified NKN-7 mol\% LT sintered at $1025^{\circ} \mathrm{C}$. However Skidmore et al ${ }^{22}$ found this composition to be tetragonal at room-temperature; variations in process conditions may have resulted in differing amounts of volatilization of $\mathrm{Na}, \mathrm{K}$, and $\mathrm{Li}$ oxides. Deviations in composition arising from loss of alkali metal oxides is known to alter the position of the orthorhombic-tetragonal phase transition in NKN$\mathrm{LT}^{22}$. The phases present at room-temperature in this region of the NKN-LT phase diagram will therefore be dependent on the extent of volatilization losses.

The XRD peak ratio values were higher for the $\mathrm{MnO}$ modified samples. The sample modified with $0.5 \mathrm{~mol} \% \mathrm{MnO}$ gave a value of 1.2 . For the $1 \mathrm{~mol} \% \mathrm{MnO}$ sample the peak ratio was 1.4 . The higher values of peak intensity ratio of both of the $\mathrm{MnO}$-modified samples suggest that the proportion of tetragonal phase increases on incorporating $\mathrm{MnO}$, but there continues to be a mixture of tetragonal and orthorhombic phases present in all samples.

It has been reported previously that $\mathrm{MnO}$ acts as a sintering aid in the related NKN-based system, $\left(\mathrm{Na}_{1-x} \mathrm{~K}_{x}\right)\left(\mathrm{Nb}_{1-y} \mathrm{Sb}_{y}\right) \mathrm{O}_{3}$, but it was thought that $\mathrm{MnO}$ did not affect the crystal structure significantly ${ }^{19}$. By contrast the present XRD data for the NKLNT composition, shows that the dopant induces a change in tetragonal/orthorhombic phase content, indicating that the $\mathrm{Mn}^{2+} / \mathrm{Mn}^{3+}$ ions have substituted on the perovskite lattice. The dopant may promote the stability of the tetragonal phase in the NKN$7 \%$ LT parent composition through a slight change in the position of the tetragonal-orthorhombic phase boundary on the NKN-LT phase diagram ${ }^{11,12}$.

The highest density samples were produced at a sintering temperature of $1025^{\circ} \mathrm{C}$. For unmodified NKLNT $(0 \% \mathrm{MnO})$, the density was $4.21 \pm 0.01 \mathrm{~g} / \mathrm{cm}^{3}$, increasing slightly to $4.25 \pm 0.05 \mathrm{~g} / \mathrm{cm}^{3}$ for 0.5 and $1 \mathrm{~mol} \% \mathrm{MnO}$ samples. Increasing the sintering temperature from $1025^{\circ} \mathrm{C}$ to $1050{ }^{\circ} \mathrm{C}$ led to a significant decrease in pellet density. Density values were $\sim 4.0 \mathrm{~g} / \mathrm{cm}^{3}$ for the 0 and $0.5 \mathrm{~mol} \% \mathrm{MnO}$ samples and $\sim 3.9 \mathrm{~g} / \mathrm{cm}^{3}$ for the $1 \mathrm{~mol} \% \mathrm{MnO}$ sample sintered at $1050{ }^{\circ} \mathrm{C}$. Density values for samples sintered at $1075^{\circ} \mathrm{C}$ were generally similar to the $1050{ }^{\circ} \mathrm{C}$ samples (Fig. 2). This result indicates that of the three temperatures studied, the highest pellet density was obtained by sintering at $1025^{\circ} \mathrm{C}$; there was only a slight enhancement in density for $\mathrm{MnO}$ additions. The decrease in sintered density between $1050^{\circ} \mathrm{C}$ and $1075^{\circ} \mathrm{C}$ is

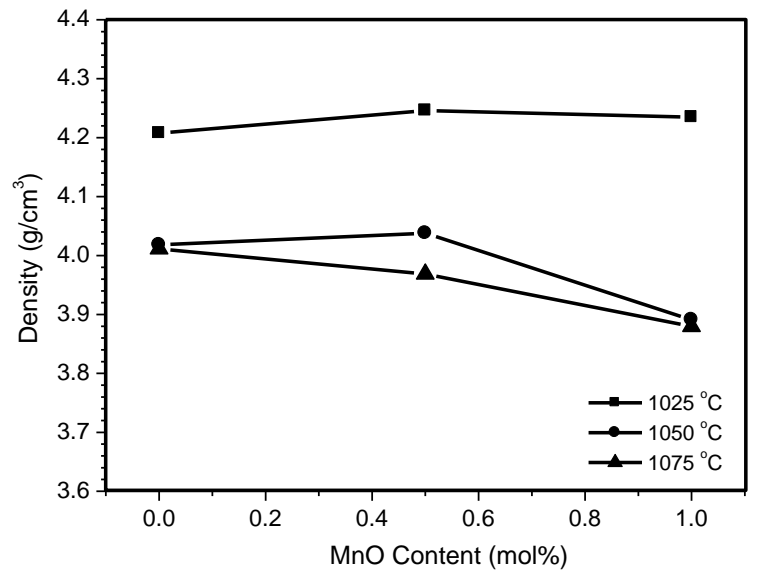

Fig. 2 Density values of $(1-x)$ NKLNT $-x$ MnO when reaction-sintered at different temperatures.

most probably due to the effects of loss of volatile oxides, but partial melting is a further possibility. Based on the value of the theoretical density for NKN-7mol\% LT calculated from lattice parameter measurements ${ }^{17,22}$ the maximum relative density of the samples was around $90 \%$.

The microstructures of samples sintered at $1025^{\circ} \mathrm{C}$ showed that the grain size and morphology were also sensitive to $\mathrm{MnO}$ content. For the $x=0$ composition, the structure was typical of secondary recrystallization (secondary grain growth), with a bimodal grain size composed of large grains up to $\sim 10-15 \mu \mathrm{m}$ in size, co-existing with $\sim 1 \mu \mathrm{m}$ grains (Fig. 3a). Incorporation of $\mathrm{MnO}$ led to more advanced secondary grain growth at $1025^{\circ} \mathrm{C}$, resulting in a greater proportion of the large (secondary) grain fraction, and a narrower range of grain sizes (Fig. 3b and $\mathrm{c}$ ).

In other perovskites such as $\mathrm{BaTiO}_{3}$, secondary grain growth is often associated with liquid phase formation. A similar mechanism leading to bimodal grain size distributions is probable in the $(1-$ $x)$ NKLNT- $x$ MnO system. However, $\mathrm{MnO}$ acts as a grain growth inhibitor in the perovskite $\mathrm{BaTiO}_{3}$ and $(\mathrm{Ba}, \mathrm{Sr}) \mathrm{TiO}_{3}$ systems. In NKLNT, it is demonstrated here to have the reverse effect, promoting secondary recrystallization such that no primary $\sim 1 \mu \mathrm{m}$ grains were evident after sintering at $1025^{\circ} \mathrm{C}$ for $2 \mathrm{~h}$. This contrasts to the unmodified NKLNT sample which showed an intermediate stage in secondary grain growth, with primary grains coexisting with larger grains. The underlying reasons for the changes in microstructure induced by $\mathrm{MnO}$ are uncertain, but the additive may alter the amount of liquid present during 


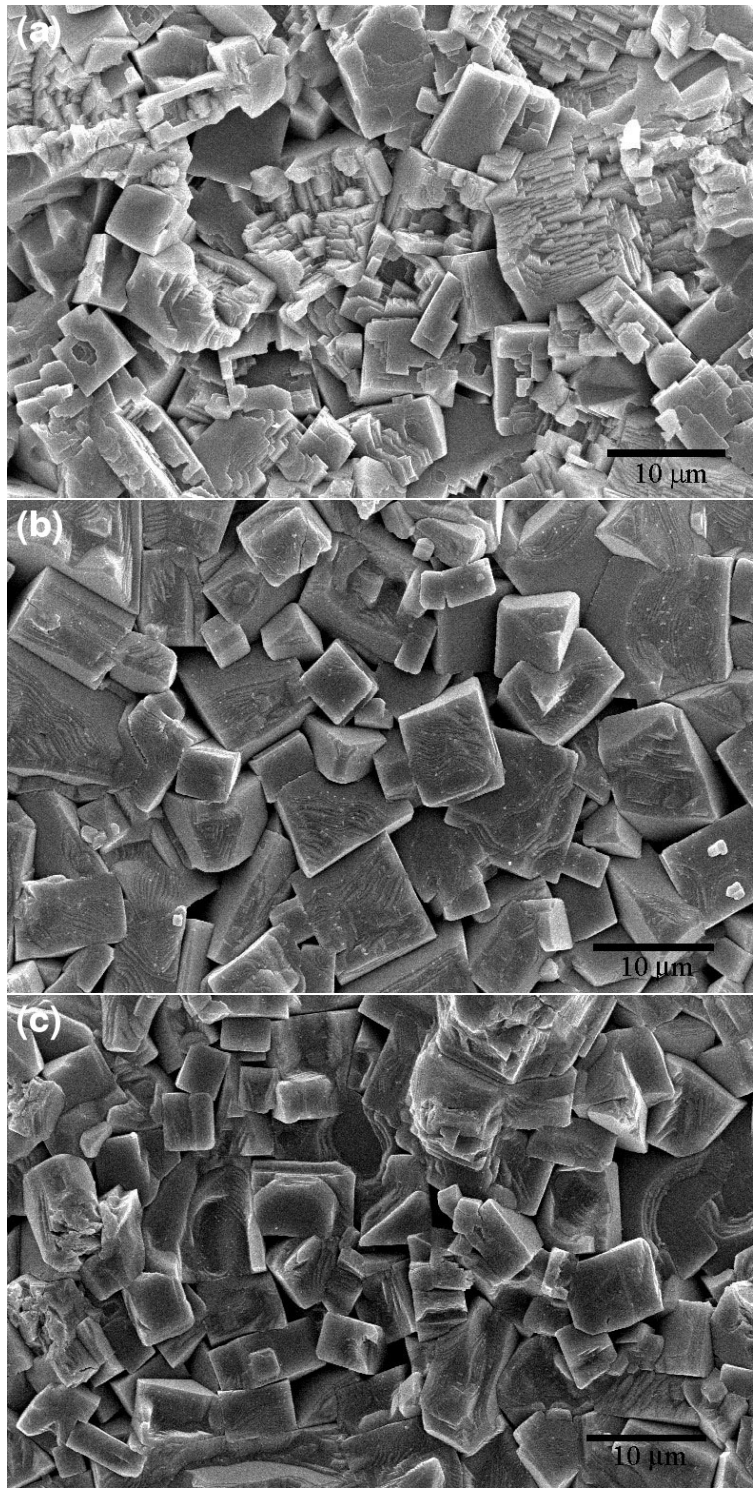

Fig. 3 SEM micrographs $(1-x)$ NKLNT- $x$ MnO samples where $x$ corresponds to: (a) $0 \mathrm{~mol} \%$, (b) $0.5 \mathrm{~mol} \%$, and (c) $1.0 \mathrm{~mol} \%$ sintered at $1025^{\circ} \mathrm{C}$ for $2 \mathrm{~h}$.

sintering. Changes in defect chemistry due to lattice substitutions may also contribute to variations in mass transport and grain growth.

Measurements of dielectric constant as a function of temperature provided further information on the phase transitions in NKLNT. The values of dielectric constant (at $1 \mathrm{kHz}$ ) as a function of $\mathrm{MnO}$ content for samples sintered at $1025^{\circ} \mathrm{C}$ are shown in Fig. 4a. The unmodified NKLNT sample showed a low-temperature broad dielectric peak due to an orthorhombic-tetragonal transition temperature
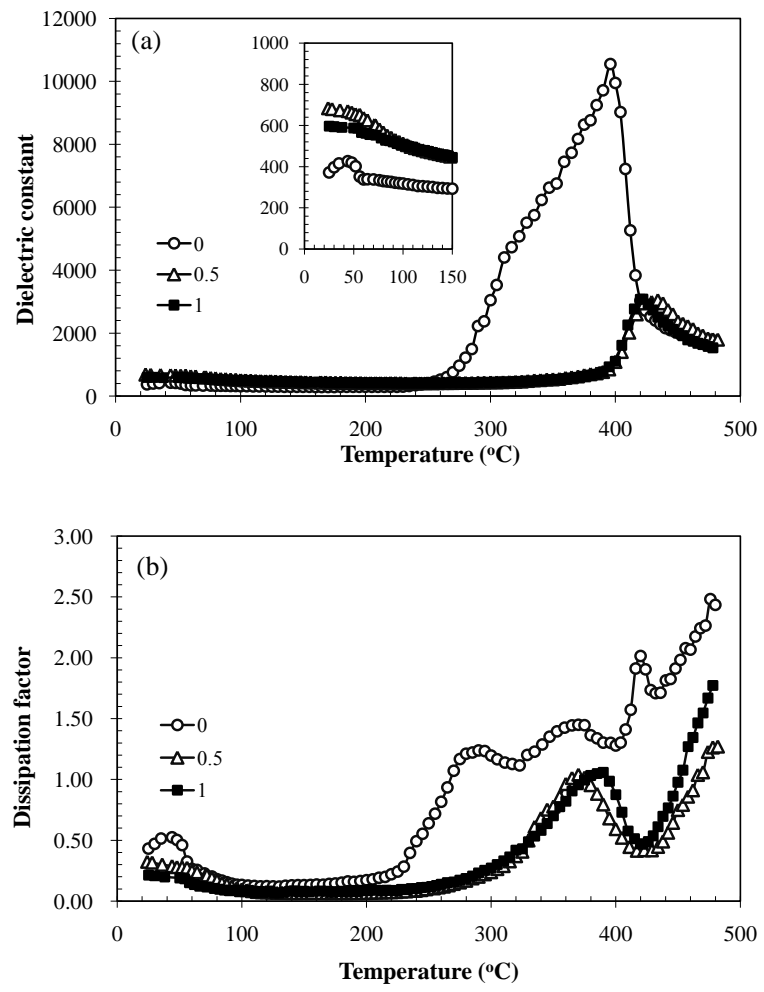

Fig. 4 Dielectric constant (measured at $1 \mathrm{kHz})$ of $(1-$ $x$ ) NKLNT $-x \mathrm{MnO}$ samples when sintered at $1025^{\circ} \mathrm{C}$ for $2 \mathrm{~h}$ : (a) dielectric constant (b) dissipation factor.

$\left(T_{\mathrm{T}-\mathrm{O}}\right)$, or possibly a monoclinic-tetragonal ${ }^{16}$ polymorphic phase transition, with a peak temperature at $\sim 45^{\circ} \mathrm{C}$ (Fig. 4a, inset). A dielectric peak at higher temperatures, $\sim 396^{\circ} \mathrm{C}$, corresponded to the tetragonal-cubic ferroelectric phase transition. Shouldering on the low temperature side of this Curie peak may be a result of chemical inhomogeneity associated with the reaction-sintering fabrication process. Regions of different composition would give slightly different Curie temperatures $\left(T_{\mathrm{C}}\right)$. Overlap of Curie peaks from regions of different composition could result in a single, broad peak as observed in Fig. 4. After modification with $\mathrm{MnO}$, the Curie peak became much sharper, consistent with improved chemical homogeneity. The $T_{\mathrm{C}}$ value increased to $\sim 434^{\circ} \mathrm{C}$ for $0.5 \mathrm{~mol} \% \mathrm{MnO}$, and $422^{\circ} \mathrm{C}$ for $1 \mathrm{~mol} \% \mathrm{MnO}$. The height of the dielectric peak reduced from $\varepsilon_{\mathrm{r}, \max } \sim$ 11000 to $~ 3000$ in the MnO-doped samples.

For the $0.5 \mathrm{~mol} \%$ and $1 \mathrm{~mol} \% \mathrm{MnO}$ samples, no dielectric peaks were evident at low-temperatures (minimum measurement temperature $=25^{\circ} \mathrm{C}$ ). The plots did however show a slight decrease in dielectric constant as temperatures increased from $25-50{ }^{\circ} \mathrm{C}$ which could signify the tail of a O-T transition which 
Table 1 The orthorhombic-tetragonal polymorphic phase transition temperature $\left(T_{\mathrm{O}-\mathrm{T}}\right)$, Curie temperature $\left(T_{\mathrm{C}}\right)$ and piezoelectric $\left(d_{33}\right)$ constant of $(1-x)$ NKLNT $-x \mathrm{MnO}$ samples when sintered at $1025^{\circ} \mathrm{C}$ for $2 \mathrm{~h}$.

\begin{tabular}{lccc}
\hline $\begin{array}{l}\text { MnO Content } \\
(\mathrm{mol} \%)\end{array}$ & $\begin{array}{c}T_{\mathrm{O}-\mathrm{T}} \\
\left({ }^{\circ} \mathrm{C}\right)\end{array}$ & $\begin{array}{c}T_{\mathrm{C}} \\
\left({ }^{\circ} \mathrm{C}\right)\end{array}$ & $\begin{array}{c}d_{33} \\
(\mathrm{pC} / \mathrm{N})\end{array}$ \\
\hline 0.0 & 44 & 396 & 190 \\
0.5 & - & 434 & 144 \\
1.0 & - & 422 & 135 \\
\hline
\end{tabular}

peaks at temperatures $<25^{\circ} \mathrm{C}$, but cryogenic measurements would be required to explore this further.

The value of dissipation factor was lowered by the incorporation of $\mathrm{MnO}$ dopant. The presence of a dielectric transition at $\sim 45^{\circ} \mathrm{C}$ in the undoped sample (Fig. 4a) complicated the comparison of roomtemperature dissipation factors between the three samples (Fig. 4b). Multiple sub-peaks in the dissipation factor of unmodified NKLNT around the Curie temperature were consistent with the premise of local fluctuations in composition. All samples showed a minimum dissipation factor in the temperature range between the two dielectric transitions. At temperatures between $100-200{ }^{\circ} \mathrm{C}$, the value fell from 0.17 for the unmodified sample to $\sim 0.06$ for the $\mathrm{MnO}$ doped samples. At temperatures above the Curie temperature the dissipation factors increased rapidly, owing to conductive losses (Fig. 4b).

The values of $d_{33}$ piezoelectric charge coefficient are shown in Table 1. In general, favourable piezoelectric coefficients for $\mathrm{BaTiO}_{3}$ and other perovskite materials result when phases co-exist at a phase boundary. The highest piezoelectric coefficient at room temperature, $d_{33}=190 \mathrm{pC} / \mathrm{N}$, was achieved in the unmodified sample for which a broad phase transition occurred with a peak-temperature of $\sim 45^{\circ} \mathrm{C}$. Dielectric measurements on NKLNT were carried out at $\sim 30^{\circ} \mathrm{C}$ and therefore the adjacent polymorphic phase transition is expected to contribute to an enhancement in the $d_{33}$ value. The value of $190 \mathrm{pC} / \mathrm{N}$ is comparable to the highest values reported for the NKN-LT system. Although MnO modifications reduced dielectric losses, they also shifted the phase transition to a lower temperature. It is assumed that this transition occurs well-below the measurement temperature in these samples and the effects of the transition on $d_{33}$ are less apparent. For this reason, $d_{33}$ values decreased from $190 \mathrm{pC} / \mathrm{N}$ in undoped ceramics to $\sim 144 \mathrm{pC} / \mathrm{N}$ and $135 \mathrm{pC} / \mathrm{N}$ for the 0.5 and $1 \mathrm{~mol} \%$ $\mathrm{MnO}$ samples respectively.

\section{CONCLUSIONS}

The introduction of $\mathrm{MnO}$ affected the structural and electrical properties of $\mathrm{Na}_{0.465} \mathrm{~K}_{0.465} \mathrm{Li}_{0.07} \mathrm{Nb}_{0.93}$ $\mathrm{Ta}_{0.07} \mathrm{O}_{3}$ ceramics, sintered at $1025^{\circ} \mathrm{C}$. Significant changes in peak intensity ratios in XRD patterns, were evidence that $\mathrm{Mn}^{2+} / \mathrm{Mn}^{3+}$ ions were substituting on the perovskite lattice. The additive increased the amount of tetragonal polymorph co-existing with orthorhombic phase. Microstructures showed evidence of secondary recrystallization, the $\mathrm{MnO}$ modified samples were more uniform in grain size, consistent with a more advanced level of secondary grain growth. The Curie temperature increased from $396^{\circ} \mathrm{C}$ to $\sim 420$ $435^{\circ} \mathrm{C}$, but the peak dielectric constant showed a 3-fold decrease in the $\mathrm{MnO}$ doped samples. The unmodified NKLNT samples gave a $d_{33}$ value of $190 \mathrm{pC} / \mathrm{N}$ decreasing to $\sim 135 \mathrm{pC} / \mathrm{N}$ in the $\mathrm{MnO}$ doped ceramics. The higher room-temperature $d_{33}$ value in the undoped samples is attributed to the beneficial effects of a orthorhombic-tetragonal polymorphic phase transition, with a peak temperature just above the measurement temperature.

\section{ACKNOWLEDGMENTS}

This work was financially supported by the Thailand Research Fund and Commission on Higher Education. The project was partly sponsored by the NANOTEC Centre of Excellence at Prince of Songkla University, Thailand.

\section{REFERENCES}

1. Jaffe B, Cook WR, Jaffe H (1971) Piezoelectric Ceramics, Academic Press, New York, p 92.

2. Moulson AJ, Herbert JM (1990) Electroceramics Materials, Properties, Applications, Chapman \& Hall, London.

3. Yimnirun R, Ananta S, Laoratakul P (2004) Dielectric properties of ceramics in lead zirconate titanate - lead magnesium niobate system. Songklanakarin J Sci Tech 26, 529-36.

4. Birol H, Damjanovic D, Setter N (2006) Preparation and characterization of $\left(\mathrm{K}_{0.5} \mathrm{Na}_{0.5}\right) \mathrm{NbO}_{3}$ ceramics. $J$ Eur Ceram Soc 26, 861-6.

5. Guo Y, Kakimoto K-I, Ohsato H (2004) Dielectric and Piezoelectric Properties of Lead-Free $\left(\mathrm{Na}_{0.5} \mathrm{~K}_{0.5}\right)$ $\mathrm{NbO}_{3}-\mathrm{SrTiO}_{3}$ Ceramics. Solid State Comm 129, 279-84.

6. Zuo R, Rödel J, Chen R, Li L (2006) Sintering and electrical properties of lead-free $\mathrm{Na}_{0.5} \mathrm{~K}_{0.5} \mathrm{NbO}_{3}$ piezoelectric ceramics. J Am Ceram Soc 89, 2010-5.

7. Saito Y, Takao H, Tani T, Nonoyama T, Takatori K, Homma T, Nagaya T, Nakamura M (2004) Lead-free piezoceramics. Nature 432, 84-7. 
8. Ahn C-W, Choi C-H, Park H-Y, Nahm S, Priya S (2008) Dielectric and piezoelectric properties of $(1-x)\left(\mathrm{Na}_{0.5} \mathrm{~K}_{0.5}\right) \mathrm{NbO}_{3}-x \mathrm{BaTiO}_{3}$ ceramics. J Mater Sci 43, 6784-97.

9. Guo Y, Kakimoto K-I, Ohsato H (2004) Phase transitional behavior and piezoelectric properties of $\left(\mathrm{Na}_{0.5} \mathrm{~K}_{0.5}\right) \mathrm{NbO}_{3}-\mathrm{LiNbO}_{3}$ ceramics. Appl Phys Lett 85, 4121-3.

10. Zhang S, Xia R, Shrout TR, Zang G, Wang J (2006) Piezoelectric properties in perovskite $0.948\left(\mathrm{~K}_{0.5} \mathrm{Na}_{0.5}\right)$ $\mathrm{NbO}_{3}-0.05 \mathrm{LiSbO}_{3}$ lead-free ceramics. J Appl Phys 100, 104108.

11. Guo Y, Kakimoto K, Ohsato H (2005) $\left(\mathrm{Na}_{0.5} \mathrm{~K}_{0.5}\right)$ $\mathrm{NbO}_{3}-\mathrm{LiTaO}_{3}$ lead-free piezoelectric ceramics. Mater Lett 59, 241-4.

12. Saito Y, Takao H (2006) High performance leadfree piezoelectric ceramics in the $(\mathrm{K}, \mathrm{Na}) \mathrm{NbO}_{3}-\mathrm{LiTaO}_{3}$ solid solution system. Ferroelectrics 338, 17-32.

13. Bomlai P, Sukprasert S, Muensit S, Milne SJ (2008) Reaction-sintering of lead-free piezoceramic compositions: $\quad(0.95-x) \mathrm{Na}_{0.5} \mathrm{~K}_{0.5} \mathrm{NbO}_{3}-0.05 \mathrm{LiTaO}_{3}-$ $x \mathrm{LiSbO}_{3} . J$ Mater Sci 43, 6116-21.

14. Matsubara M, Kikuta KSH (2005) Piezoelectric properties of $\left(\mathrm{K}_{0.5} \mathrm{Na}_{0.5}\right)\left(\mathrm{Nb}_{1-x} \mathrm{Ta}_{x}\right) \mathrm{O}_{3}-\mathrm{K}_{5.4} \mathrm{Cu} \mathrm{Ta}_{10} \mathrm{O}_{29}$ ceramics. J Appl Phys 97, 114105.

15. Chen R, Li L (2006) Sintering and electrical properties of lead-free $\mathrm{Na}_{0.5} \mathrm{~K}_{0.5} \mathrm{NbO}_{3}$ piezoelectric ceramics. $J$ Am Ceram Soc 89, 2010-5.

16. Du H, Liu D, Tang F, Zhu D, Wancheng Z (2007) Microstructure, piezoelectric, and ferroelectric properties of $\mathrm{Bi}_{2} \mathrm{O}_{3}$-added $\left(\mathrm{K}_{0.5} \mathrm{Na}_{0.5}\right) \mathrm{NbO}_{3}$ lead-free ceramics. $J$ Am Ceram Soc 90, 2824-9.

17. Skidmore TA, Comyn TP, Milne SJ (2009) Temperature stability of $\left(\left[\mathrm{Na}_{0.5} \mathrm{~K}_{0.5} \mathrm{NbO}_{3}\right]_{0.93}-\left[\mathrm{LiTaO}_{3}\right]_{0.07}\right)$ lead-free piezoelectric ceramics. Appl Phys Lett 94, 222902.

18. Hao J, Xu Z, Chu R, Zhang Y, Li G, Yin Q (2009) Effects of $\mathrm{MnO}_{2}$ on phase structure, microstructure and electrical properties of $\left(\mathrm{K}_{0.5} \mathrm{Na}_{0.5}\right)_{0.94} \mathrm{Li}_{0.06} \mathrm{NbO}_{3}$ leadfree ceramics. Mater Chem Phys 118, 229-33.

19. Lin D, Kwok KW, Tian H, Chan HWL (2007) Phase transitions and electrical properties of $\left(\mathrm{Na}_{1}-{ }_{x} \mathrm{~K}_{x}\right)$ $\left(\mathrm{Nb}_{1-y} \mathrm{Sb}_{y}\right) \mathrm{O}_{3}$ lead-free piezoelectric ceramics with a $\mathrm{MnO}_{2}$ sintering aid. J Am Ceram Soc 90, 1458-62.

20. Bomlai P, Sinsap P, Muensit S, Milne SJ (2008) Effect of $\mathrm{MnO}$ on the phase development, microstructures, and dielectric properties of $0.95 \mathrm{Na}_{0.5} \mathrm{~K}_{0.5} \mathrm{NbO}_{3}$ 0.05 $\mathrm{LiTaO}_{3}$ ceramics. J Am Ceram Soc 91, 624-7.

21. Zuo R, Fu J, Su S, Fang X, Cao JL (2009) Electrical properties of manganese modified sodium potassium lithium niobate lead-free piezoelectric ceramics. J Mater Sci Mater Electron 20, 212-6.

22. Skidmore TA, Milne SJ (2007) Phase development during mixed-oxide processing of a $\left[\mathrm{Na}_{0.5} \mathrm{~K}_{0.5} \mathrm{NbO}_{3}\right]_{1-x}-\left[\mathrm{LiTaO}_{3}\right]_{x}$ powder. J Mater Res 22, 2265-72.

23. ICDD (2001) Powder Diffraction File No. 32-0822, In- ternational Centre for Diffraction Data, Newton Squre, PA.

24. ICDD (2001) Powder Diffraction File No. 71-0945, International Centre for Diffraction Data, Newton Squre, PA. 